\title{
"Adivinhação" na Índia antiga: algumas notas
}

\author{
CARLOS ALBERTO DA FONSECA \\ MÁRIO FERREIRA \\ Departamento de Letras Clássicas e Vernáculas \\ Faculdade de Filosofia, Letras e Ciências Humanas \\ Universidade de São Paulo
}

\begin{abstract}
RESUMO: Os autores têm por objetivo rastrear, em fontes literárias sânscritas, aspectos diversos relativos ao conceito de "adivinhação". Na primeira parte, com um exame do léxico sânscrito da "adivinhação", articula-se um repertório da prática em questão. A seguir, procura-se ampliar o exame no âmbito específico do Yogadarçana. Finalmente, por meio de seleçäo de passagens extraídas da literatura sânscrita, exemplifica-se o convívio estreito com aspectos variados da "adivinhação" e sua utilização como recurso para a urdidura dramática da narrativa.
\end{abstract}

PALAVRAS-CHAVE: Literatura sânscrita, lexicologia sânscrita, adivinhação na índia antiga, siddhi, Yogadarçana, teatro sânscrito.

O presente texto tem por objetivo rastrear, em fontes literárias vazadas em sânscrito, aspectos diversos relativos ao conceito de "adivinhação". Divide-se ele em três partes - independentes mas complementares. Na primeira, mediante levantamento léxico efetuado com recurso às obras de referência de Monier-Williams, pretende-se articular um repertório - amplo, difuso e, certamente, lacunar - da vigência e prática do conceito em questão, mapeando-se, dessa forma, alguns dos quadrantes do imaginário sânscrito. Na segunda, isolando-se um dos vocábulos do referido repertório, procura-se ampliar o exame da questão no âmbito específico de um sistema metafisico-filosófico, a saber, o Yogadarçana. Na terceira, por meio da seleção de passagens extraídas de obras expressivas de vários gêneros da literatura sânscrita, visa-se a, por um lado, exemplificar o convívio estreito, socialmente referendado, com aspectos variados da "adivinhação" e, por outro, apontar a utilização do conceito enquanto recurso para a urdidura dramática da narrativa.

Ressalvando-lhes o caráter exploratório e não exaustivo, espera-se que as notas seguintes possam contribuir para uma primeira incursão no estudo do universo da "adivinhação" na İndia antiga. 


\section{O léxico sânscrito da "adivinhação"}

O estudioso do sânscrito que se dispuser a fazer um levantamento de seu léxico em relação a qualquer campo semântico enfrentará uma primeira dificuldade básica, relativa mais aos problemas de elaboração do único Reverse Dictionary existente do que a questões inerentes à própria língua. Trata-se do English and Sanskrit Dictiona$r y$, de Monier Monier-Williams, publicado em $1851^{1}$, a cujo prefácio, do mesmo ano, fazem-se as referências seguintes.

Informa ali seu compilador sobre a função e o cunho principais que desejava para sua obra e nela imprimiu: "Deve-se admitir que um estudante dificilmente poderá praticar a composição e também a tradução em uma língua dificil se os auxilios usuais não forem colocados à sua disposição. $\mathrm{O}$ fato de tais auxílios ainda não serem disponiveis em sânscrito deve-se à grande dificuldade encontrada em compilar um bom dicionário de inglês e sânscrito" (p. I). E mais adiante: "No que diz respeito aos missionários e outros filantropos e estudiosos, cujo objetivo tem sido o de comunicar a verdade escritural e cientifica aos nativos cultos, por meio de sua língua clássica, e aos incultos, por meio de suas línguas vernaculares, a falta de qualquer auxílio à composição tem certamente gerado as dificuldades que seus trabalhos experimentam" (p. II). Para tanto auxiliar grupos tão diferenciados na prática da composição em sânscrito, o compilador elaborou sua obra "com uma consideração atenta dos melhores equivalentes sânscritos dos termos e das expressões modernas e com uma disposição cuidadosa, em cada verbete inglês, de seus inúmeros equivalentes, em sua ordem própria e em sua própria conexão com suas muitas nuances de significado" (p. IV-V). Além disso, "quando foi possível dar uma lista completa das palavras sânscritas sinônimas, isso foi feito. Ao mesmo tempo, tentou-se dispor as palavras na ordem de sua utilidade" (p. VII). O autor referese, ainda, a outra situação: a de palavras inglesas das quais não se podia oferecer um representante sânscrito preciso (tais como camera obscura, steam-boat, telescope etc. - todas elas vivas na cultura ocidental, mas desconhecidas no mundo indiano antigo). A esse respeito, faz a seguinte afirmação: "Ao traduzir tais palavras, pagou-se um tributo aos hindus [sic] cultos em seu estudo do inglês. A compreensão das idéias européias por parte dos nativos cultos é tão necessária para um entendimento recíproco quanto para a compreensão das idéias hindus [sic] por nós mesmos" (p. VIII).

Estão aí, alinhavados rapidamente, os limites principais que se deve traçar para o levantamento do léxico sânscrito da "adivinhação" que se propõe aqui. Em primeiro lugar, algumas palavras relativas à mais do que relativa MODERNIDADE dos equivalente sânscritos e de seus sinônimos com relação aos verbetes ingleses: não se pode esquecer de que o sânscrito, depois do século VII d.C., embora fosse utilizado cada vez menos na literatura, nunca deixou de ser utilizado de alguma maneira pelas castas cultas indianas em sua vida cotidiana e não deixou de ter seu léxico aumentado. Por esta razão, a grande maioria dos termos constantes do English and Sanskrit Dictionary (a que nos referiremos daqui em diante como ESD), levantados com base em glossários e 
dicionários clássicos, mas principalmente no léxico do sânscrito de meados do século XIX, não é ratificada no Sanskrit and English Dictionary (referido aqui como SED), do mesmo Monier-Williams, publicado em $1899^{2}$, que foi preparado com base unicamente nos textos literários e científicos escritos em sânscrito clássico. Desta maneira, uma camera obscura aparece no ESD como uma definição: sändhakärakutīpațalaniveçitaç cākșușayantraviçeșo yaddvärena antarasthaçvetaphalake pratibimbitā vahihsthā visayà drçyā bhavanti ou - "espécie de aparelho que se leva aos olhos, que tem uma figura humana ou uma silhueta de paisagem ali encaixados e por cuja abertura tornam-se visiveis, num fundo branco interno, aqueles objetos por reflexo" - diferentemente de tea: "No Sanskrit equivalent, cahā may be used"; do já lembrado telescope: (mahā)dūradarçakayantra "aparelho para visão a (grande) distância" e cakṣusayantra "aparelho para levar aos olhos" (poderia este termo servir para "óculos"? O ESD não traz o verbete glasses) e dos equivalentes sânscritos para, por exemplo, European (yuropiya), England (çvetadvipa "Ilha Branca", inglandanämako deçah̆ "a terra chamada Iñglanda", com o -a final não pronunciado, como ocorre em todas as palavras do repertório sânscrito que se trasladaram para o hindi) etc.

Nestas condições, fica dificil saber se os termos para o campo da "adivinhação" elencados no ESD (exceto, claro, aqueles que o SED abona em textos clássicos) correspondem a um inventário do léxico sânscrito que se desenvolveu após o século VII ou a traduções feitas, com recurso a formas perfeitamente possíveis no léxico do sânscrito clássico, pelos nativos cultos de meados do século XIX que auxiliaram seu compilador. Além disso, fica dificil também, tendo em mente o critério exposto pelo autor ${ }^{3}$, estabelecer um grau qualquer da UTILIDADE dos termos — ou melhor, de sua maior ou menor utilização ou expressividade.

Feitos esses comentários, passa-se agora a apresentar o léxico sânscrito da "adivinhação" colhido no ESD, acompanhado de algum esclarecimento, dando aos termos uma tradução literal, listando-os na ordem do mesmo dicionário (às vezes isolando em primeiro lugar o primeiro termo de cada verbete) e, no caso daqueles abonados pelo SED, os significados parciais ou totais ali apontados.

\section{Divination}

1.1. gananā: "cálculo", "enumeração"; "suposição" (SED);

1.2. ganakatā: "astrologia" (SED); não está, no ESD, em "Astrology";

1.3. pakșigatihastarekhädilaksanād bhavişyadanumāna: "inferência do futuro a partir da qualidade (laksana) do movimento dos pássaros e das linhas das mãos" - e

1.4. paksigatihastarekhādilakșañāc chubhāçubhakathana: "relato do bom e do ruim a partir da qualidade do movimento dos pássaros e das linhas das mãos": nestas duas acepções, ecos de mancias muito difundidas, mas sem abono, quanto à Índia antiga, na literatura védica, épico-bramânica ou clássica;

1.5. pürvalaksanapariks $\bar{a}$ : "exame (parikșā) de um pürvalakșana", termo que o 
SED dá como "indicação de algo que está para ocorrer" [literalmente: "marca favorável, qualidade (lakșana) originada no passado (pürva)"];

1.6. çakunaparikssana: o çakuna, segundo o SED, é um "pássaro (especialmente um grande pássaro ou um pássaro de bom augúrio ou mau agouro)" e também uma "espécie de hino ou canção (cantado em festivais para se assegurar a boa sorte)"; além disso, "qualquer objeto auspicioso ou de bom augúrio, um augúrio ou prognóstico (em geral; raramente 'um mau agouro')"; o mesmo SED dá os termos Çakunadipaka "Luz dos çakuna(s)", Çakunärnava "Onda de çakuna(s)" e Çakunāvalï "Guirlanda de çakuna(s) como "títulos de obras" sobre augúrios, os termos çakunaçāstra como o genérico de "tratado sobre augúrios" e çakunopadeça como o de "doutrina dos augúrios". O termo parikșana é sinônimo do "exame" anterior;

1.7. pürvacihnaniriksana: para o SED, cihna é um "sinal" qualquer ou um "signo zodiacal" e nirikșana, o "ver" ou o "aspecto dos planetas". Em traduções literais, um "sinal dado pelo signo no passado" ou "o ato de ver o aspecto dos planetas no passado";

1.8. bhavisyatsūcana: segundo o SED, bhavisyat é "o que está para acontecer, o futuro"; sūcana é uma "indicação". Lit. "uma indicação do futuro".

\section{Prediction}

2.1. bhāvikathana: lit. "relato do futuro" (bhāvi e bhavisyat são formas sinônimas);

2.2. bhavisyatkathana "relato do futuro"; anāgatakathana "relato do não acontecido"; agrakathana "relato do anterior"; pürvakathana "relato do passado"; pradarçana "previsão"; anāgatapradarçana "previsão do não acontecido"; bhavisyadbodhana "compreensão do futuro"; bhavisyadvākya "fala sobre o futuro"; ou simplesmente $u b$ bodhana "lembrança".

\section{Prognostic}

3.1. pürvalaksana: ver 1.5 ;

3.2. pürvacihna: ver 1.7;

3.3. pürvarüpa: segundo o SED, "indicação de algo que se aproxima, um augúrio"; lit. "um fenômeno originado no passado";

3.4. pūrvalin̄ga: não abonado pelo SED. Vale alguns comentários: lingga é um termo de muita fortuna no léxico sânscrito: é uma "marca", um "sinal", um "signo", uma "prova", "evidência", um "sinal de culpa", corpus delicti; na Lógica, a marca invariável que prova a existência de algo num objeto (na proposição "Onde há fumaça há fogo" - yatra yatra dhümas tatra tatra pāvakah — "fumaça" é o lin̄ga); na Medicina, um "sintoma de doença"; na Poética/Retórica, nome dado a uma palavra que serve para fixar o significado de outra: em kupitas makara-dhvajas, a palavra kupita restringe o significado de makaradhvaja (lit. "que tem o animal makara como emblema") a Kāma, o deus do Amor, de que é um epíteto; 
3.5. pürvasūcakacihna: lit. "sinal (ou aspecto zodiacal) que indica o passado";

3.6. laksana: ver 1.5;

3.7. cihna: ver 1.7;

3.8. nimitta: no SED, "augúrio", que também dá nimittavid "que conhece augúrios, um astrólogo" (não está no ESD em "Astrologer"); formas sinônimas (SED): pratyaya "prova" e hetu "causa";

3.9. ajanya: no SED, como adjetivo: "impróprio de ser produzido ou nascido, inadequado para a humanidade"; como substantivo: "qualquer portento desfavorável à humanidade, tal como um terremoto";

3.10. çakuna: ver 1.6 ;

3.11. bhāvisücakacihna: "sinal (ou signo zodiacal) que indica o futuro"; bhavisyadudbodhakacihna "sinal (ou signo zodiacal) que dá compreensão do futuro"; segundo o SED, bhāvi também é algo "predestinado, inevitável";

3.12. anistasūcakacihna: lit. "sinal (ou signo zodiacal) que indica algo anișta", isto é, (segundo o SED) "indesejado, desvantajoso; desfavorável; mau, errado, ominoso"; o SED abona o termo anistasücaka como "mau presságio".

\section{Foreboding}

4.1. anistasūcaka: ver 3.12;

4.2. anistapradarçana: lit. "previsão de algo anista";

4.3. pürvalakṣañàd anistānumāna: lit. "inferência de um anista a partir de marca do passado".

\section{Omen}

\subsection{Em geral:}

5.1.1. pürvalakșana: ver 1.5;

5.1.2. pürvacihna: ver 1.7; pürvalinga: ver 3.4;

5.1.3. çubhāçubhalakşana: para lakşana, ver 1.5; quanto a [çubha + açubha], o SED o dá como os pares de contrários "agradável e desagradável, fortunado e desafortunado, bom e mau, auspicioso e inauspicioso"; quanto ao termo completo, o SED abona os significados de "marca/sinal de boa ou má sorte" e "augúrio bom ou mau";

5.1.4. mañgalāmañgalalakșana: segundo o SED, mañgala (aman̄gala, com que está fundido no composto, é o seu contrário) significa "felicidade, bem-estar; algo auspicioso ou que leva a um final feliz (por ex., um bom augúrio, uma prece, uma bênção, um enfeite ou amuleto auspiciosos, um festival ou qualquer cerimônia solene em ocasiões importantes); um bom costume antigo", etc. Dá, também, um grande número de termos compostos iniciados com mañgala, todos eles relacionados com o "desejar boa sorte ou fazer algo que a traga", como: 
mañgalakarana "o ato de se dizer uma prece para o êxito antes de se empreender qualquer ação";

mañgalagāthikā "uma canção solene";

mañgalaghata "jarro auspicioso", uma vasilha cheia de água oferecida às divindades durante os festivais;

mañgalaçabda "palavra auspiciosa, felicitação";

mañgalasütra "cordão da felicidade", o cordão do casamento, colocado pelo noivo no pescoço da noiva e usado por ela enquanto o marido viver;

e muitos outros, dentre os quais destacamos ainda mañgalādeçavrtta "alguém que lê a sorte", que ocorre no Mănavadharmaçāstra, o conhecido "Código de Manu", na estrofe IX. $258^{4}$. Literalmente, o termo que aqui se comenta poderia significar, sem abono do SED, "sinal de felicidade ou infelicidade";

5.1.5. bhāvișūcakacihna, bhavisyatsūcakacihna: formas sinônimas; ver 3.11;

5.1.6. çakuna: ver 1.6;

5.1.7. cihna: ver 1.7 ;

5.1.8. laksana: ver 1.5;

5.1.9. ajanya: ver 3.9;

5.1.10. nimitta: ver 3.8;

5.1.11. utpāta: sem qualquer referência no SED;

5.1.12. pürvarüpa: ver 3.3; o futuro";

5.1.13. bhavisyadudbodhacihna: lit. "sinal (ou signo zodiacal) que faz lembrar

5.2. Bom augúrio:

5.2.1. sucihna: lit. "bom sinal (ou signo zodiacal)";

5.2.2. sulakșana: segundo o SED, "ato de observar ou examinar cuidadosamente; marca ou caracteristica boa ou auspiciosa";

5.3. Mau agouro:

5.3.1. durlaksana: contrário de 5.2.2; segundo o SED, "marcado maleficamente";

5.3.2. duçcihna: contrário de 1.7; sem referência no SED;

5.3.3. avacihna: sinônimo de 5.3.2; idem;

5.3.4. avalaksana: sinônimo de 5.3.1; idem;

5.3.5. apaçakuna, duhçakuna: conträrios de 1.6; idem;

5.3.6. anistasücakacihna: ver 3.12; idem;

5.3.7. açübhalaksana: ver 5.1.3; idem;

5.3.8. açubhacihna: "sinal inauspicioso", idem;

5.3.9. amañgalacihna: "sinal de infelicidade"; idem;

5.3.10. upalinga: contrário de liñga, ver 3.4; abonado pelo SED como "um portento, fenômeno natural considerado como portador do mal". 


\section{Prophecy}

6.1. bhavisyatkathana: ver 2.2;

6.2. bhavisyakathana, bhävikathana: ver 2.1;

6.3. bhävivisayakathana: "relato de coisas do futuro";

6.4. bhavisyatpradarçana, bhavipradarçana: "previsão do futuro";

6.5. bhāvisyaddarçana: "visão do futuro";

6.6. pradarçana: ver 2.2 ;

6.7. bhāvivisayapradarçana: "previsão de coisas do futuro";

6.8. bhavisyatsūcaka: ver 1.8;

6.9. bhāvinirüpana: "visão do futuro";

6.10. agranirūpana: "visão do anterior";

6.11. siddhādeça: lit. "indicação de poder"; quanto ao termo siddha: lit. "o que foi ganho, conquistado, adquirido por meio de habilidades, dotado de faculdades sobrenaturais" (neste último sentido, o SED remete ao termo siddhi, cujo significado técnico vem estudado na parte II deste trabalho), "sagrado, santo, divino; efetivo, poderoso, miraculoso, sobrenatural"; "um ser semidivino de grande pureza e perfeição do qual se diz possuir as 8 faculdades sobrenaturais" elencadas na parte II; "qualquer sábio, profeta ou vidente inspirados",; "qualquer figura sagrada ou grande santo (especialmente aquele que atingiu um dos estados de beatitude, chamados sâlokya 'estar na mesma esfera ou mundo', sāmīpya 'estar próximo a uma divindade', sārüpya 'estar com a forma de uma divindade' e sāyujya 'estar absorvido por uma divindade')"; "um grande adepto ou mágico que adquiriu poderes sobrenaturais". Quanto ao termo composto completo, o SED abona-o como "predição de um vidente; alguém cujas predições são cumpridas, um profeta, um adivinho, alguém que prevê a sorte".

\section{Malediction}

7.1. çāpa: "maldição, praga, insulto, imprecação, interdição, proibição" (SED); note-se o termo çāpāstra, lit. "que tem como arma a maldição" — designativo do homem santo cujas maldições se exercem até mesmo sobre as divindades;

7.2. abhiçāpa "maldição, acusação; calúnia" (SED); çāpa "maldição, imprecação, praga" (SED); çāpana, çāpatha idem; pariçāpa "maldição, insulto" (SED); $\bar{a} k$ roça, äkroçana "insulto" (SED); avakroça "imprecação" (SED); upakroça "reprovação, censura" (SED); bhartsana "ameaça, chantagem; maldição" (SED); durvākya "linguagem insultuosa ou áspera" (SED), lit. "fala ruim; amañgalavacana, akalyānavacana, lit. "fala inauspiciosa"; aman̄galecchā, lit. "desejo inauspicioso"; maukharya "linguagem grosseira, difamação, insulto, calúnia" (SED).

\section{Soothsaying}

8.1. çakunapariksana: ver 1.6; 
8.2. ganană: ver 1.1;

8.3. daivajña: lit. "conhecimento do daiva", ver 10.1 .

\section{Curse (Malediction)}

9.1. çāpa: ver 7.1;

9.2. abhiçāpa, çapatha, çapa, çapana, pariçāpa, ākroçana, avakroça, bhartsana: ver 7.2 ;

9.3. găli: "fala injuriosa, invectiva, execração" (SED);

9.4. mandaväñcha: lit. "desejo infeliz".

\section{Termos para o agente da "adivinhação"}

10.1. daivajña: lit. "que conhece o daiva", palavra importante no contexto em exame. Segundo o SED, "pertencente aos deuses ou deles proveniente, divino, celestial", donde "fatal, dependente do destino" e também "vontade ou poder divinos, destino, fado, chance" (podendo-se, então, traduzir daivajña literalmente como "que conhece o destino"; o SED, todavia, não faz esse exercício, nem aponta os termos próprios). Também "uma divisão da Medicina que consiste no uso medicinal de encantamentos, preces etc."

O termo daiva entrou na formulação de inúmeros compostos lexicalizados importantes, dentre os quais vale citar (todos elencados no SED): daivakrta "feito por vontade divina", donde "natural"; daivakovida "familiarizado com os destinos do homem" - no feminino, "uma mulher que vê a sorte"; daivacintaka "que reflete sobre o destino", um "astrólogo"; daivacintā "fatalismo, astrologia"; daivalekhaka "astrólogo, homem que vê a sorte" (note-se que um lekhaka é "alguém que escreve" — liga-se à raiz LIKH "escrever") —, "alguém que faz cálculos", ou então "cálculo"; daivavid "astrólogo" - lit. "que conhece o destino"; daivätyaya "perigo ou mal resultantes de fenômenos naturais incomuns"; daivānurodhin "obediente ao destino ou à vontade dos deuses";

\subsubsection{Diviner}

daivajña, çakunaparīșaka, pūrvacihnanirīkṣaka, nimittajña, pakșigatihastarekhādilakșan̄ād bhavisyatsǘcaka;

\subsubsection{Predictor}

bhāvikathaka, bhavisyatkathaka, bhavisyadvaktr, agravädin, pūrvavādin ${ }^{6}$, pradarçaka, anāgatapradarçaka, bhāvivaktr, bhävidarçaka, daivajña, naimittika;

10.2.3. Prognosticator

pürvasūcaka, agrasūcaka "que indica o que houve antes", pūrvalakșanena bhavisyatsūcaka "que indica o futuro por sinais do passado"/bhāvisücaka/bhäَvidarçakalanägatadarçaka, pürvalakșanajña, pürvacihnajña;

10.2.4. De foreboding

anistasūcaka, anistapradarçaka, pūrvalaksanajña, pürvalin̄gajña, agrasūcaka; 


\subsubsection{Foreteller}

agravādin, bhavisyadvaktr, bhavişadvādin, bhāvivaktr, anāgatajñapaka "que conhece o não acontecido", pradarçaka, bhāvidarçaka, daivajña;

\subsubsection{Prophet}

bhavisyadvaktr, bhavisyadvādin, bhāvivaktr, bhavisyatkathaka, bhāvikathaka, pradarçaka, bhavisyatpradarçaka, bhāvipradarçaka, bhä̀vişyaddarçaka, bhāvisūcaka, bhavisyatsūcaka, anāgatadaŗ̧aka, anāgatavaktr, agranirüpaka, "que desvenda o que houve antes", pūrvanirüpaka, bhāvinirüpaka, anägatajñapaka, bhāvijñapaka, pūravid "que conhece o passado", dūradarçin, bhāvidarçin", daivajña;

\subsubsection{Soothsayer}

daivajña: ver 10.1;

sāmoatsarika: lit. "que conhece o ano"; um astrólogo?;

sävitrka: lit. "que conhece o movimento do Sol"; um astrólogo?

\section{O conceito de siddhi no Yogadarçana}

Vinculado igualmente à catalogação dos poderes divinatórios, comparece o vocábulo siddhi, em cuja acepção geral - "qualquer habilidade, faculdade ou capacidade incomum" (SED) - se enquadram várias das configurações semânticas das palavras listadas acima, mas de que importa, sobremodo, considerar o sentido técnico, ióguico - "aquisição de poderes sobrenaturais por meios mágicos ou faculdade superior assim adquirida" (SED) -, porquanto nele se pode entrever a "fabricação" duma arte divinatória particular.

Não cabe, evidentemente, no âmbito desta nota, uma exposição do sistema Yoga ${ }^{8}$. Não obstante, com vistas a fornecer o balizamento para a compreensão do conceito de siddhi, esclareça-se que constitui esse sistema um dos seis darçana (lit. "ponto de vista") em que se articula a especulação filosófico-religiosa da Índia antiga, caracterizado metafisicamente pela concepção dualista do universo, que se considera tecido pela integração entre "mônadas vitais" (purușa) e "matéria inerte" (prakrti) manifesta em três "modalidades" (guna), estando ambos os princípios relacionados indissoluvelmente e condenados a interminável "ronda de transmigração" (saìnsāra).

Congregando práticas imemoriais, de datação impossivel, embora certamente préárias, visa o Yoga, em suma, por meio de uma técnica de ascese e um método meditativo, a propiciar a libertação do princípio purusa, restituindo-lhe o caráter de espírito puro, imóvel, sempiterno, consciência especular de si mesmo.

Fixadas no Yogasūtra ${ }^{9}$, de Patañjali, obra cuja redação é atribuída aos séculos III ou IV d.C., articulam-se as etapas que conduzem à libertação referida. Congregam elas, num processo hierárquico e progressivo: 1. adestramento da arte do refreio (yama), a qual implica a recusa introjetada de matar, mentir, roubar, dar curso ao impulso sexual e apegar-se à matéria; 2. adestramento na arte da disciplina (niyama), a qual postula: asseio corporal, 
serenidade, ascese, estudo (da metafisica ióguica) e identificação com Içvara (puruşa protótipo do praticante), a conquista das quais faculta a entrega aos exercícios seguintes: 3 . āsana, posturas fisicas imóveis, desenhadas para possibilitar, no nível do corpo, o termo das flutuações mentais e dos turbilhões da consciência; 4 prānāyāma, exercícios respiratórios que visam à regularização do fluxo pneumático, transformando-o em atividade controlada voluntariamente; e 5. ekāgratā, concentração totalizante num único objeto, o qual pode tanto ser físico quanto conceitual. Conquistadas as etapas anteriores, que permitem a concentração unificada da psique, obtém-se acesso a 6. pratyāhāra, retraimento sensorial, faculdade que consiste em cortar os vínculos dos órgãos de sensações com os objetos externos e que propicia os recursos psíquicos para as etapas seguintes, consistentes de 7 . dhärañă, fixação do pensamento num único ponto, a qual visa a "penetrar" o objeto visado, assimilando-lhe as caracteristicas essenciais, e 8. dhyãna, meditação, formulação de redes conceituais articuladas em função das matrizes exaradas pela dhäraṇă.

Cumpridas as etapas referidas, pode-se, então, realizar a experiência do samādhi, êxtase ióguico, representado pelo triunfo da gnose contemplativa, a qual permite penetrar a essência dos objetos e revelar a constituição fundamental do ser, queimando-lhe os vestígios subliminares de vidas pregressas e detendo a ação inflexível do mecanismo transmigratório.

Epifenômenos do samāadhi, manifestam-se, dessarte, os siddhi, os "poderes miraculosos", que fornecem a justificativa metafisico-psíquica para o dom da "adivinhação", entendida esta segundo o repertório fixado na nota anterior, e que assim se podem catalogar, segundo o Yogasütra (cap. III, aforismos 16-54):

1. Conhecer o passado e o futuro;

2. Conhecer as vidas anteriores, próprias e alheias;

3. Conhecer os estados mentais dos outros seres;

4. Possuir a arte da invisibilidade;

5. Conhecer a hora exata da morte;

6. Possuir a força de um elefante;

7. Mediante a meditação sobre o Sol, conhecer a constituição do universo;

8. Mediante a meditação sobre a Lua, conhecer a posição e o movimento das estrelas;

9. Conhecer a constituição e o funcionamento do corpo;

10. Possuir a arte de suprimir os desejos de comida e bebida;

11. Possuir o domínio sobre os elementos; e

12. Possuir o domínio sobre a estrutura física do próprio corpo.

Quanto a este último poder, afirmam tanto Vyāsa ${ }^{10}$ como Bhoja ${ }^{11}$ (ambos, exegetas do texto) que se manifesta ele em oito modalidades diversas, congregando poderes de magnitude arqui-sobrenatural, a saber:

a) animan ("diminuição"), faculdade de reduzir o corpo à dimensão do átomo;

b) laghiman ("leveza"), faculdade de tornar o corpo tão leve quanto a lã;

c) gariman ("peso"), faculdade de tomar o corpo tão pesado quanto se deseja; 
d) mahiman ("grandeza"), faculdade de aumentar a dimensão do corpo;

e) prākāmya ("irresistibilidade"), faculdade de realizar todo e qualquer desígnio, dobrando os obstáculos intervenientes;

f) içitva ("supremacia"), faculdade de controlar as funções orgânicas e mentais;

g) vaçitva ("domínio"), faculdade de submeter todo e qualquer ser à própria vontade;

h) kāmāvasāyitva ("supressão da paixão"), faculdade de existir com isenção de todo e qualquer desejo.

Tais os poderes que a tradição do Yogadarçana confere ao devoto que se entrega à prática prescrita. Elucubração bizarra desprovida de senso ou recusa onipotente de aceitar os limites da condição humana — não cabe aqui definir-lhes o caráter. Registre-se, no entanto, que, na história da tradição sânscrita, cumpre o homem-deus, o siddha, dotado de faculdades miraculosas, uma função nuclear, exibindo-se como formalização de um ideário forjado coletivamente. (Leiam-se, nesta óptica, as bio-hagiografias de Buddha, Jina, Rāmānuja, Gandhi...)

Seja como for, o convívio com o limiar da sobrenaturalidade representa uma das arraigadas formas do imaginário indiano. É o que atestam os passos literários consignados a seguir.

\section{A "adivinhação" na literatura sânscrita}

Múltiplas são as passagens literárias que evocam aspectos particularizados da "adivinhação". No que segue, procura-se exemplificar tais aspectos, enquadrando-os numa sumária tipologia tripla, caracterizada por a) pressentimentos e premonições, b) predições e maldições e c) sinais de boa sorte, e estudando-se a ocorrência desses tipos numa mesma obra (Abhijñānaçakuntalam, de Kālidāsa), no propósito de verificar-lhes a função narrativa e dramática.

\section{Tipologia}

\section{A. Pressentimentos e premoniçס̃es}

Enquadram-se aqui os passos que implicam percepções impositivas, acompanhadas de sensações fisicas perturbadoras, relativas a acontecimentos futuros, que, na seqüência dramática, inevitavelmente vêm sempre a se cumprir.

A. 1. Mrcchakatikam, de Çūdraka, drama do século II a.C.

No nono ato, lamenta-se Cārudatta a caminho do tribunal, onde será julgado por um crime que não cometeu:

O corvo crocita com voz áspera, os criados do Ministro chamam por mim repetidamente e meu olho esquerdo treme com violência: tais sinais de mau agouro [animit- 
ta, ver 3.8, supra] deixam-me ansioso. [Caminhando e olhando à frente.] Esse corvo, pousado numa árvore desgalhada e voltado para o sol, aponta-me o olho esquerdo. Não há dúvida de que uma horrível calamidade cairá sobre mim. [Olhando para outra direção.] Ah! Uma serpente! Essa enorme serpente, que estava atravessada em meu caminho, fuzila-me de ódio, com os olhos fixos em mim, o corpo negro como carvão, a língua vibrando para fora da boca, as quatro presas brancas à vista. Os meus pés estão soldados ao chão, e neste não há lama alguma. Meu olho esquerdo treme, e também meu braço esquerdo. E eis aí um outro pássaro gritando sem parar. Tudo isso indica a mais terrivel morte — não há nenhuma dúvida.

[Ao tentar entrar no recinto da Corte de Justiça, perturbado, bate a cabeça na porta:]

Ai de mim! Ainda outro [sinal de mau agouro]. Meu olho esquerdo treme, o corvo grita, a serpente barra o caminho. Que o destino [daivata, ver 10.1, supra] me seja favorável! ${ }^{12}$

Ao cabo do tenso julgamento, é Cärudatta condenado injustamente à morte, por intriga de adversários.

\section{B. Predições e maldições}

Cabem aqui as passagens que incluem previsões positivas (no caso de predições) e negativas (no caso de maldições) sobre acontecimentos futuros, que, no desenvolvimento narrativo, igualmente vêm a se efetivar.

B.1. Daçakumāracarita, de Dandin, romance do século VI (ou VII) d.C.

Tendo o rei Rājahamina desaparecido numa batalha, Vasumatí, sua esposa, pretende pôr fím à vida. Os Ministros e o Capelão tentam dissuadi-la, dizendo-lhe:

Ó bendita Rainha, a morte do Rei é incerta. Além disso, habita teu útero um príncipe belo e delicado que, como disseram os astrólogos [daivajñakathita, ver 10.1, supra], deverá exterminar o inimigo, inchado de orgulho, e será o supremo senhor de toda a Terra. Sendo assim, é impróprio de tua parte dares cabo à vida agora. ${ }^{13}$

\section{B.2. Daçakumāracarita}

Um brâmane, transfigurado em cisne, medita, assentado sobre um lótus. Perturbado pela interferência do rei Çāmbu, lança-lhe, furioso, as seguintes palavras:

Rei, dado que tu, orgulhoso de tua soberania, me insultaste, sem qualquer motivo, quando eu, devotado há muito ao estudo, estando imerso em contemplação, gozava de suprema felicidade neste lótus, sofrerás as agonias da separação de tua amada, como castigo por esse ato reprovável. [...] Rei, não recairá sobre ti, nesta vida, $o$ fruto da maldição [çāpaphala, ver 8.1, supra]. Mas, devido à infalibilidade de minhas palavras, serás, em tua próxima vida, o amado do cisne-fêmea em que me transformarei] de belos olhos de lótus. Por dois meses acorrentado, como castigo por me pertubares agora por dois átimos, sofrerás a angústia da separação de tua 
amada e só depois desfrutarás os prazeres de um reino, em companhia de tua amada, por longo tempo. ${ }^{14}$

\section{B.3. Meghadūta, de Kălidāsa, poema do século V d.C.}

Um certo Yakșas [ser semidivino, encarregado da guarda dos jardins e dos tesouros], que negligenciara por completo o cumprimento de seus deveres, tendo sido por esta razão privado do poder de grandeza [mahiman, ver II, supra], devido à maldição [çāpa, ver 8.1, supra] lançada por seu mentor, segundo a qual deveria ele sofrer por um ano a dor pela separação de sua amada esposa, instalou-se nos eremitérios das encostas do Ramagiri [...]. . $^{15}$

Compreende-se, na passagem, a ênfase aposta na explicitação da maldição lançada ao Yakșas, considerando-se o núcleo temático da obra - a nuvem mensageira dos amantes. Conservando o Yaksas a posse do siddhi mahiman, poderia ele alcançar com facilidade a esposa ou dela ter notícias, por meio da concentração mental.

B.4. Mālavikāgnimitram, de Kālidāsa, drama do século V d.C.

Mălavikā, criada da rainha Dhārin̄ī, desperta a paixão do rei Agnimitra, mas a aproximação entre ambos é travada por impedimentos de casta. Depois de inúmeras peripécias, revela-se, ao final, a verdadeira origem ksatriya da suposta criada:

Senhor, ouvi. Esta jovem, vivendo ainda seu pai, foi informada em minha presença, por um sábio dotado de poderes sobrenaturais [siddhādeçena sādhunā, ver 6.1.11, supra], num festival em honra de uma divindade, de que, durante um ano, deveria permanecer na condição de serva, após o que desposaria um homem da mesma casta. Estando ela ao vosso serviço e cumprindo assim a profecia [ădeça, ver 6.1.11, supra], aguardarei o momento oportuno [para revelar a origem de Malavikā] e penso que agi de modo correto. ${ }^{16}$

\section{B.5. Ratnāvali, de Harșa, drama do século VII d.C.}

A rainha Vâsavadattā, esposa de Vatsa, conta, entre as suas servas, com os cuidados de Sāgarikā, por quem o rei está apaixonado. Ao final, descobre-se que a serva é, na verdade, Ratnāvalī, filha do rei de Simhala, e que, a seu respeito, rezava uma profecia (pratyaya, ver 3.8, supra) de um prognosticador (siddhādeça, ver 6.1.11, supra) dando conta de que desposaria ela no futuro um cakravartin, um "soberano universal"."

\section{Sinais de boa sorte}

Desenhos, traços e sinais impressos no corpo, geralmente nas mãos, indicando a excepcionalidade do ser que os apresenta. Configuração específica da carta astrológica, assinalando a posse de faculdades particulares. Conformação incomum da natureza, traduzida por sinais inusitados que autorizam a consecução de um ato.

C.1. Daçakumäracarita 
Prossegue o relato de B.1, supra:

Então, completada a gravidez, Vasumati, em boa hora, deu à luz um filho dotado de todas as marcas auspiciosas [sakalalakșanaks.ita, cf. 1.5, supra, laksana]. ${ }^{18}$

\section{C.2 Daçakumāracarita}

Rājavāhana, filho de Vasumatī e Rājahamisa, já adulto, engajado na tarefa de restaurar um reino usurpado, dirige-se a uma floresta:

Rājavāhana, divisando bons augúrios e pássaros faustos no caminho [mañgalasücakam çubhaçakunam vilokayan, ver 1.6 e 5.1.4, supra], avançando um certo trecho, adentrou o coração da floresta de Vindhya $\bar{a}^{-19}$

\section{C.3. Daçakumāracarita}

Um brâmane, disfarçado em "adivinho" (kārtāntiko näma bhütvă $\overline{-20}^{20}$ percorre as estradas à cata de uma esposa dotada das qualidades por ele exigidas. Avistando uma jovem, observa-a de alto a baixo e percebe que

suas mãos - as palmas e os dedos vermelhos - estão marcadas com vários desenhos auspiciosos [punyalekh $\bar{a}^{21}$, tais como trigo, peixe, lótus, vaso etc. ${ }^{22}$

\section{C.4. Mrcchakatikam}

No sexto ato, representa-se o embate entre vários oficiais de polícia, um dos quais, Candanaka, assim se expressa, caracterizando o adversário prestes a sucumbir:

Quem tem o Sol na oitava casa? Ou a Lua na quarta? Ou Vênus na sexta? Ou Marte, o filho da Terra, na quinta? Digam-me: Quem tem Júpiter na sexta casa? Ou Saturno, o filho do Sol, na nona? ${ }^{23}$

\section{C.5. Mrcchakatikam}

No sétimo ato, Cārudatta, que pertence à casta dos brâmanes, exclama, ao avistar um monge budista:

Como?! Diante de mim, a visão de um monge budista, um sinal de mau augúrio?! [anäbhyudayika, abonado pelo SED como "não auspicioso, infeliz, de mau agouro"] $]^{24}$

\section{C.6. Mrcchakatikam} nefasta:

No oitavo ato, um vita ("dândi"), passando por uma rua, presencia uma cena Oh! Uma árvore caiu em meu caminho! E, quando caía, matou uma mulher. Ó 
maligna! Que perversa ação cometeste! O olhar da mulher morta por tua queda nos traz azar! Eis um sinal de mau agouro [animitta, ver 3.8 , supra]. ${ }^{25}$

\section{A "adivinhação" em Abhijñanaçakuntalam}

A obra em epigrafe, de autoria de Kālidāsa (século V d.C.), constitui um dos mais prestigiados dramas do teatro indiano clássico. Várias são as razões que lhe justificam o renome. Por um lado, tem ela, como núcleo narrativo, a história mesma do personagem basilar da constituição da indianidade, a saber, Bharata, filho do rei Duşyanta e de Çakuntalā, de cujo nome deriva até mesmo a designação atual da República Indiana (Bhārata). Por outro lado, integrando-se na modalidade nātaka, o gênero literário mais cultivado no teatro clássico, caracterizado pela articulação dos cinco samidhi ("junções": unidades estruturais resultantes da soma de uma "matéria prima" acional e um "estado de espírito") prescritos pelos tratados de dramaturgia, utiliza ela com virtuosidade todos os 64 "motivos" dramáticos ( $(\bar{n} g a)$ catalogados pelos mesmos tratados, devendose ressaltar que constitui imperativo estético a utilização de apenas 23 de tais motivos. Ademais, apresenta ela brilhante desenvolvimento narrativo, porquanto lança mão de várias estratégias dramáticas, uma das quais baseada no recurso ao tensionamento acional obtido pelo emprego dos motivos relacionados à "adivinhação".

No que segue, reproduzem-se os episódios vinculados aos motivos em questão.

1. Numa floresta, prepara-se o rei Dusyanta para alvejar uma gazela. No instante em que tensiona o arco, é interrompido por um brâmane, acompanhado por discípulos, o qual the pede que detenha o gesto, por ser sagrada aquela parte da floresta, estando os animais sob a proteção do eremitério. 0 rei obedece.

Diz, então, o eremita, em tom profético: "Tal gesto é bastante digno de vós, ó descendente de Puru. Que tenhais um filho adornado de todas as virtudes, soberano do mundo". ${ }^{26}$

Fazendo eco às palavras do eremita, repetem os discípulos, erguendo as mãos (gesto fausto de bendição): "Que tenhais um filho, o soberano do mundo."27

Ressalte-se, aqui, a importância dramática da repetição do núcleo da profecia por vozes em coro, acompanhada por gesto de bênção.

2. Aceitando o convite do eremita, o rei dirige-se ao eremitério, onde terá alojamento. Ao aproximar-se do local, "age como se tivesse percebido um augúrio [nimittam, ver I.3.8, supra]"

e diz:

Este eremitério é tranqüilo, mas meu braço estremece. Como pode isso acontecer num local como este? Bem dizem que até mesmo os portões dos eventos predestinados [bhavitonya, lit. "que devem acontecer no futuro"] se abrem em todos os lugares. ${ }^{28}$ 
3. No eremitério, Duşyanta conhece Çakuntalā, filha adotiva no brâmane Kāçyapa e de Gautamí, e filha natural do brâmane Kauçika e da ninfa Menakā. Apaixonam-se. Casam-se por consentimento mútuo. Dușyanta retorna à Corte, prometendo voltar em breve. Deixa um anel, com o seu nome gravado. Passa o tempo. Numa ocasião, Çakuntalā, recostada à porta de sua casa, sonhando com Dușyanta, não ouve o pedido de hospitalidade feito por um brâmane errante. Furioso com a ofensa involuntária de Çakuntalā, lançando-lhe uma maldição (çaptvā, forma absolutiva da raiz ÇAP, de que deriva o termo çāpa, ver I.7.1, supra), condena a jovem a ser esquecida por aquele com quem sonhava. Intercedem as criadas e obtêm do brâmane um abrandamento da maldição. Diz ele: "Não posso voltar atrás em minhas palavras. Todavia, a visão do anel suspenderá o efeito da maldição [çāpa]. "29

4. Dada a ausência prolongada de Duşanta, e estando Çakuntalā grávida, decide Kạçyapa enviar a filha à Corte. As criadas, que ocultaram de Çakuntalä o episódio da maldição, enfeitam-na com adornos auspiciosos tirados de um vaso contendo objetos auspiciosos (mañgalapätra, ver I.5.1.4, supra). Chegam meninos do eremitério portando presentes oferecidos pelas árvores da floresta: uma veste auspiciosa (mañgalya, de mañgala) de seda, branca como a lua, laca vermelha para passar na sola dos pés e guirlandas de flores, a propósito das quais diz uma das criadas: "Esse dom indica que desfrutarás a soberania na casa de teu marido.",30

5. Recomendam as criadas a Çakuntalā que mostre o anel a Duṣyanta, sem explicar a ela a necessidade desse gesto. Diz Çakuntalā: "Treme a parte esquerda de meu corpo [ver A. 1, supra] em face desse risco."31

6. Çakuntalā chega ao palácio de Dușanta, acompanhada da mãe e dos irmãos. Diz: [percebendo um augúrio (nimitta, ver I.3.8, supra)]. "Oh! Por que treme meu olho direito?"

Gautamī, percebendo o sinal nefasto, diz à filha: "A má-sorte [amañgala, ver I.5.1.4, supra] seja afastada. Os deuses da Casa de teu marido te proporcionem coisas boas [sukha, termo genérico de felicidade]. ${ }^{\text {"32 }}$

7. Sob o jugo da maldição, Duṣyanta não reconhece a esposa, em cena dramática, marcada pelo tenso diálogo entre a mãe e os irmãos de Çakuntalā e o rei. Intervém o capelão, que, para solucionar o impasse, diz:

Que esta senhora more até o parto em minha casa. Se me perguntares por que digo isto, explico que os sábios dizem que terás um filho marcado, ao nascer, com o signo da roda do carro [cakravartin, ver nota 31]. Se a criança nascer com essa marca [lakșana, ver I.1.5, supra], a mãe será aceita no gineceu. Caso contrário, deverá ser devolvida ao pai. ${ }^{33}$

8. Confiada ao capelão, Çakuntalā desaparece, arrebatada por uma emissária de Menakā. Entrementes, um pescador recolhe o anel que Çakuntalä perdera ao banhar-se num rio durante a viagem. Levado ao rei, o anel dissipa a maldição. Duṣyanta mortifica-se. Passa o tempo. Regressando de uma batalha no céu contra os inimigos do deus 
Indra, Dusyanta dirige-se à morada de Āditi e Māñca. Aí encontra e reconhece o filho. Reconcilia-se com Çakuntalä. Rememoram-se as ações anteriores, salientando-se o efeito cruel da maldição [çāpa]. Por fim, Máríca, tomando a palavra, profetiza sobre o destino do filho do nobre casal:

Ele será um soberano universal [cakravartin] nos dias futuros. Guerreiro incomparável, atravessará o oceano num carro e conquistará toda a Terra. Aqui é chamado de Sarvadamana, porque a tudo doma. Será depois chamado de Bharata, porque será o sustentáculo do mundo. ${ }^{34}$

Para finalizar, algumas observações adicionais sobre o uso literário da "adivinhação".

1. Conforme prescrevem os manuais de dramaturgia, deve toda peça, seja o gênero a que se vincule ela, iniciar-se por uma estrofe augural, denominada nandi (lit. "prosperidade", "felicidade") ${ }^{35}$, procedimento que tem por objetivo obter de Çiva, patrono do teatro e alvo da estrofe, a graça de uma representação correta. Assim também, deve toda peça encerrar-se por uma fala igualmente augural (praçasti, lit. "proveito"), devotada, esta, no entanto, não à companhia dos atores, mas à platéia, para a qual se solicita a proteção dos deuses.

2. Bons augúrios promete igualmente o'trecho terminal do sarga I do "Livro das Origens" do épico Rāmāyana:

Esta história sagrada, que os pecados aniquila, que é santa e semelhante aos Vedas, aquele que a contar livre ficará de suas faltas. Esta lenda de renome faz viver o homem que a recita, rodeado pelos filhos, pelos netos e por numeroso cortejo, e o engrandece no céu, por ocasião de sua morte. $O$ brâmane que a recita adquire o império da eloqüência; o ksatriya, o domínio do mundo; o vaiçya vê o seu comércio prosperar, até mesmo o çüdra, ouvindo-a, obtém uma situação superior. ${ }^{36}$

Preocupação semelhante percorre as estrofes findantes do épico Mahābhārata, cujo çloka final reza o seguinte:

Tal é a história do épico. Todo aquele que o ouvir integralmente purificado será por completo. Purgadas serão suas culpas, como a escuridão pelo Sol. E gozará ele o reino de Vișnu, tal se o próprio Viṣnu fosse. ${ }^{37}$

3. Quanto aos Purāna ${ }^{38}$, textos que integram igualmente a massa das narrativas épicas, recorrem eles a curiosa estratégia redacional, descrevendo como profecias eventos históricos já transcorridos - transmutando, portanto, o histórico em possibilidade, e o real em termo ideal concretizado. Articula-se, desse modo, um jogo entre texto e leitor, encarregando-se este de "adivinhar" no presente a conformação das virtualidades pretéritas contidas naquele.

4. Traços messiânicos fornecem os fundamentos de formulação do mito de Viṣnu, mote de inúmeras obras. ${ }^{39}$ Encarnando periodicamente a fim de conjurar situações caó- 
ticas, voltará a divindade - prevêem todos os seus adeptos - sob a forma do avatāra eqüestre Kalkin, incumbindo-lhe destruir o mundo atual, no fito de conferir-lhe nova ordem cosmológica.

A diversidade, como se pode perceber, marca o universo da "adivinhação" nas vertentes do pensamento indiano. Um traço de união, no entanto, congrega-lhes as manifestações - a saber, o primado da palavra enquanto suporte dos atos divinatórios e enquanto instrumento de nomeação pletórica dos fenômenos percebidos sobrenaturalmente por mercê dos siddhi.

Matriz do real, catálogo do possivel, exerce, de fato, a palavra um papel crucial nas manifestações divinatórias, porquanto se integram estas na morfologia geral do sagrado $^{40}$, a qual, no âmbito da cultura da Índia clássica, não se pode conceber desvencilhada da correlata articulação verbal.

O poder sacramental da palavra - portanto, o poder de saturar o real de plena significação -, eis, de fato, uma das linhas de força fundamentais do pensamento indiano. Conforme pontifica o tratado de estética Kävyaprakāç̧a I, 2, de Mammata: ${ }^{41}$

\section{Fama}

Fortuna

Saber miúdo

Termo do Mal

Gozo diário

O Ser da Amada

-O poema é

$O$ poema faz

\section{Notas}

1- As citações e referências obedecem à $4^{\mathrm{a}}$ edição indiana, de 1976, da Motilal Banarsidass, Delhi.

2- As citações e referências obedecem à edição de 1974, da Motilal Banarsidass, Delhi.

3- Idem, p. vii: "Na verdade, para os propósitos de composição em prosa ou tradução, aconselha-se ao estudante escolher a palavra sânscrita que está em primeiro lugar na lista, ou pelo menos fazer sua seleção entre os primeiros equivalentes enumerados."

4- A passagem faz parte de uma enumeração de "ladrões que se mostram em público": "os que recebem suborno por chantagem ou mentira, os jogadores, os mângalädeçavrtta, os falsificadores e os îksanika". Não há convergência, entre os tradutores do texto para os significados dos termos não traduzidos aqui. Para G. Bühler, The Laws of Manu, os māngalādeçavrtta são "those men who live by teaching the performance of, or by performing for others, auspicious ceremonies" ou "men who live by reciting auspicious hymns"; para A. L. Deslongchamps, Lois de Manou, são "les discurs de bonne venture". Quanto ao segundo termo, iksanika: para Bühler, trata-se de um "fortune-teller"; para Deslongchamps, "un chiromancien". 
Vale dizer que o SED abona apenas a primeira tradução de Deslongchamps e a segunda de Bühler.

5- Convém, aqui, alertar para a impropriedade - cometida com muita frequência nos meios sanscritistas e, com maior regularidade, nas obras de mera divulgação de informações relativas à cultura indiana antiga - de se traduzir o termo rși como "vidente", seguindo as soluções inglesa e francesa que o dão como equivalente a, respectivamente, seer e voyant. A etimologia do termo sânscrito não oferece nenhuma base para essa operação: deriva ele da raiz R.S. que dá idéia de "movimentação no espaço" - donde "ir, movimentar-se, caminhar, andar, vaguear". Derivando dai, $r s i$ significa literalmente "um andarilho". E devia ser este, realmente, o estatuto de um rssi na Índia antiga: uma classe de brâmanes que compunha poemas (reunidos depois na coletânea chamada Rgveda) e caminhava de aldeia em aldeia recitando-os, ou cantando-os, em cerimônias rituais ou em justas poéticas. Se, todavia, como quer a tradição mística hindu (com base na qual se fixaram os termos inglês e francês, tributários estes de uma equivocada compreensão dos siddhi referidos no Yogadarçana - ver parte II), esses poemas foram escritos no éter pelas divindades e ouvidos (çruti "audição" chama-se com efeito a tradição memorizada dos textos iniciais revelados) por esses poetas, essa "revelação" aponta certamente para fatos e fatores ligados à estratégia de dominação ária no período védico ou a uma concepção bastante original da inspiração poética - mas não deve encaminhar a reflexão para questões ligadas à "adivinhação".

6- Os termos vaktṛ e vādin são formas sinônimas de kathaka, "aquele que fala sobre":

7-O termo darçin é forma sinônima de (pra-) darçaka.

8- Para uma introdução acurada ao Yogadarçana, ver Mircea Eliade, Le Yoga - Immortalité et Liberté.

9- Baba, 1979, passim.

10- Baba, 1979, ad III, 44.

11-Eliade, 1975, p. 97 nota.

12- Çüdraka, 1972, p. 323-5.

13-Dandin, 1979, p. 9 (devanágari) e 6.

14- Dandidin, 1979, p. 47 (devanágari) e 32-3.

15- Kälidāsa, 1974, p. 2-4.

16- Kälidāsa, 1977, p. 155.

17- Harșa, 1933, p. 5.

18-Dandin, 1979, p. 12 (devanágari) e 8.

19- Dandin, 1979, p. 23 (devanágari) e 15.

20- Segundo o SED, um kārtāntika é um astrologer, um fortune teller.

21- Para o SED, trata-se de "sinais de boa sorte". Quanto ao desenho do trigo, indica ele, conforme sua localização, abundância de riqueza, farta progênie masculina, boa sorte etc.

22- Dandin, 1979, p. 158 (devanágari) e 112.

23- Çü̉raka, 1972, p. 229. As posições planetárias, no caso, assinalam, especificamente: Sol na oitava: morte; Lua na quarta: aflição do estômago; Vênus na sexta: desagregação mental; Marte na quinta: destruição e perdas; Júpiter na sexta: sofrimento e aflição causadas por inimigos; e Saturno na nona: perda de riqueza, indigência.

24- Çüdraka, 1975, p. 251.

25- Çüdraka, 1972, p. 291.

26- No original, cakravartin, utilizado, aqui, deliberadamente, em sua dupla acep̧̧ão de "soberano do mundo" e "Imarcado pelo sinal da] roda do carro", ou seja, um sinal fausto de soberania, conforme será explicitado nos atos V e VII. 
27-Kālidāsa, 1972, p. 11.

28- Kälidāsa, 1972, p. 15.

29- Kālidāsa, 1972, p. 17.

30-Kālidāsa, 1972, p. 109.

31- Kālidāsa, 1972, p. 123.

32- Kālidāsa, 1972, p. 139.

33- Kālidāsa, 1972, p. 157.

34- Kälidāsa, 1972, p. 243-5.

35- A propósito, leia-se o seguinte comentário de Sylvain Lévi, 1963, p. 131-2: "le mot nändă semble indiquer une idée de commencement heureux: le poteau de la porte s'appelle nändikāa, et chez les Jainas, $n \bar{a} n d i$ désigne une cérémonie d'introduction aux çrāvana-kṛtyāni, à l'exposé de la doctrine, à la récitation des añgas; un des sūtras jainas est intitulé Nandisūtra, et Weber le traduit: Introduction destinée à porter bonheur. Pour assurer mieux le succès de la bénédiction, il faut y faire entrer les mots de bon augure, tels que: le bilva, la conque, le lotus, le kokila, le lis, et surtout le nom de la lune, car c'est elle qui contient l'ambroisie, le meilleur des rasas (liquides et sentiments), et quand la lune est satisfaite, le rasa coule en abondance".

36- Vâlmiki, 1963, p. 100.

37- Lal, 1980 , p. 370.

38- Assim, por exemplo, o Viṣnupurāna.

39- Por exemplo, Mahäbhāratä XII, 12941 e seq.; Raghuvamiça III, 36 e V, 24; Gïtagovinda I, 1.

40- A propósito, ver Mircea Eliade, Tratado de história das religiões e $O$ sagrado e o profano, passim.

41-Mammata, 1965, p. 6. Tradução dos autores.

\section{Referências Bibliográficas}

BABA, Bangali. The Yogasütra of Patañjali. Delhi: Motilal Banarsidass, 1979.

BÜHLER, G. The Laws of Manu (trad.). Delhi: Motital Banarsidass, 1982. Vol. XXV da coleção The Sacred Books of the East.

ÇŪDRAKA . Mrcchakatikă. Estabelecimento de texto e tradução inglesa de M. R. Kale. Delhi: Motilal Banarsidass, 1972, $3^{\mathrm{a}} \mathrm{ed}$. rev.

DANDIN. Daçakumāracarita. Estabelecimento de texto e tradução inglesa de M. R. Kale. Deihi: Motilal Banarsidass, 1979, reimpr. da 4 ed. (1966).

DESLONGCHAMPS, A. L. Lois de Manou. Tradução e estabelecimento de texto. Paris: Levrault, 1930.

ELIADE, Mircea. Le Yoga - Immortalité et Liberté. Paris: Payot, 1975.

ELIADE, Mircea. Tratado de história das religiões. Lisboa: Martins Fontes, s.d.

ELIADE, Mircea. O sagrado e o profano. Lisboa: Livros do Brasil, s.d.

HARSA. Ratnāvalī. Estabelecimento de texto e tradução francesa de Maurice Lehot. Paris: Les Belles Lettres, 1933.

KĀLIDĀSA. Abhijñänaçakuntalam. Estabelecimento de texto e tradução inglesa de C. R. Devadhar e N. G. Suru. Delhi: Motilal Banarsidass, 1972, $3^{\mathrm{a}}$ reimpr. da 1 ed. (1934).

KĀLIDĀSA. Mālavikāgnimitram. Estabelecimento de texto e tradução inglesa de C. R. Devadhar. Delhi: Motilal Banarsidass, 1977, reimpr. da 3 ed. (1966). 
KĀLIDĀSA - Meghadūta. Estabelecimento de texto e tradução inglesa de M. R. Kale. Delhi: Motilal Banarsidass, 1974, 8 ed.

LAL, P. The Mahäbhärata of Vyasa. Delhi: Vikas Publishing House, 1980, $3^{\mathrm{a}} \mathrm{ed}$.

LÉVI, Sylvain. Le théâtre indien. Paris: Collège de France, 1963, $2^{\mathrm{a}}$ tiragem (1 ${ }^{\mathrm{a}}$ ed.: 1890). Bibliothèque de L'École des Hautes Études, $83^{\circ}$ fascículo.

MAMMATA, M. Kōovyaprakāça. Texto original, editado por Raghunath Damodar Karmarkar. Poona: Bhandarkar Institute, 1965.

MONIER-WILLIAMS, Monier. English and Sanskrit Dictionary. Delhi: Motilal Banarsidass, 1976, $4^{\text {a }}$ ed. Indiana. ( $1^{\mathrm{a}}$ ed.: 1851$)$.

MONIER-WILLIAMS, Monier. A Sanskrit and English Dictionary. Oxford: Clarendon Press, 1974, $5^{\text {a }}$ reimpr. da 1 ed. (1899).

VĀLMT̄KI. El Ramayana. Tradução espanhola de Juan B. Bergua Madrid: Classicos Bergua, 1963.

FONSECA, C. A., e FERREIRA, M. "Divination" en Inde antique: quelques notes. Clássica, São Paulo, 4: 81-101, 1991.

RÉSUMÉ: Les auteurs ont prétendu un rapprochement, à partir de quelques sources littéraires sanskrites, de plusieurs aspects rapportant au concept de "divination". Dans la prémière partie, avec un examen du léxique sanskrit de la "divination", on articule un répertoire de la pratique cotidienne en question. Ensuite, on étend l'examen pour l'ambiance propre au Yogadarçana. Finalement, moyennant un choix de passages extraits de la littérature sanskrite, on donne des situations exemplaires de la fréquentation étroite avec les aspects divers de la "divination" et son emploi dans la trame discoursive des narratives.

MOTS CLÉS: Littérature sanscrite, lexicologie sanskrite, divination en inde antique, siddhi, yogadarçana, théatre sanskrit. 